\title{
Proyecto de cambio en el destino de una obra pía (de la enseñanza del latín a la dotación de becas universitarias)*
}

\author{
Justo García Sánchez**
}

Recibido: 24 de enero de 2015 • Aprobado: 28 de febrero de 2015

\section{Resumen}

Este artículo contiene un estudio histórico detallado sobra la enseñanza del latín en Asturias durante el siglo XVI, cuidadosamente documentado en los archivos históricos de Oviedo que es el lugar hacia el cual se dirige este trabajo; por tal razón contiene algunas trancripciones paleográficas literales de textos antiguos que iluminan la cuestión y que, sin duda, ofrecen un aporte a la enseñanza de la Filosofía y la Teología. Cabe aclarar que la citación varía en este texto por tratarse, en su mayoría, de fuentes documentales antiguas que reposan en archivos históricos.

Palabras clave: universidad, dominicos, becas, latín.

* Producto de las investigaciones del autor.

** Jurista e historiador; Catedrático de Derecho Romano de la Universidad de Oviedo, Correo electrónico: jgarcias@uniovi.es 


\title{
Project of change in the date of a pious work (from the teaching of latin to granting college scholarrships)
}

\begin{abstract}
This article contains a detailed historical study about teaching Latin in Asturias during the sixteenth century, carefully documented in the historical archives of Oviedo which is the place to which this paper is addressed; for this reason it contains some literal paleographic transcriptions of ancient texts that illuminate the issue and, undoubtedly, offer a contribution to the teaching of Philosophy and Theology. It is to be clarified that the citation varies in this text because, mostly, they are ancient documentary sources that are found in historical archives.
\end{abstract}

Keywords: University, Dominicans, scholarships, Latin.

\section{Projet de changement du destin d'une œuvre pieuse (de l'enseignement du latin a l'attribution de bourses universitaires)}

\section{Résumé}

Cet article contient une étude historique détaillée à propos de l'enseignement du latin aux Asturies pendant le XVI siècle, soigneusement documenté dans les archives d'Oviedo, vers où ce travail se dirige ; pour cette raison, il contient des transcriptions paléographiques littérales de textes anciens qui illuminent la question et que, sans aucun doute, offre une contribution à l'enseignement de la philosophie et de la théologie. Il convient de clarifier que la référence varie dans ce texte étant constitué, en grade partie, d'anciennes sources documentaires qui reposent dans les archives historiques.

Mots-clés: Université, dominicains, bourses, latin. 
El prócer asturiano, inquisidor general de España, Fernando de Valdés, natural de la villa de Salas (Gonzáles, 1968)1' , buen conocedor de las penurias educativas que atravesaba el Principado de Asturias, adoptó muy pronto, ya durante su primera etapa de vida episcopal, la resolución firme de fundar y poner en ejecución un pequeño colegio, bajo la advocación de San Gregorio, ubicado en la capital del territorio natal (Benito Ruano, 1970).

Con reglas poco numerosas, pero bastante precisas, en cartas que remitió al cabildo catedralicio ovetense, a través de uno de sus hermanos nominado Hernando, que era capitular de dicha persona jurídica, manifiesta en 1557 su riguroso funcionamiento académico, bajo el gobierno dcl preceptor, entonces el licenciado Custodio, proveniente de la Universidad de Alcalá, al que sucedería posteriormente el licenciado Herrera, discípulo del Dr. Matamoros, del mismo Estudio Complutense, fijando detalladamente, en carta de 15 de octubre de 1561, las reglas del gobierno colegial (ACO. Libro de actas capitulares. Sign. 9, fol. 36r):

En el colegio se ha de dar de comer a quince personas, que son doce colegiales y el preceptor principal, que ha de ser Rector, con otro preceptor o repetidor y un familiar, y señalándose a diez mil maravedíes para la comida de cada uno de estos, cada año, se podrán sacar la comida y salario para la mujer que tuviese cargo de lavar la ropa y para un despensero que hubiese de traer comida y guisarlo, y desde ahora se podrá cumplir el numero de los doce colegiales y familiar; y los que se hubiesen de recibir de nuevo, por lo menos, han de saber leer bien latin y la doctrina cristiana, y que tengan habilidad y sean pobres y cristianos viejos, que no sean vecinos ni hijos de vecino de la ciudad de Oviedo, por el aparejo que tienen de poderse mejor sustentar, y por otros buenos respetos.... Podranse dar desde luego a los dichos colegiales sendas ropas o sotanas de paño pardo o de otro color, con que anden en el Colegio y fuera de el (Canella Secades, 1985).

Como recordaba Canella Secades (Canella Secades, 1985), el estudio de la lengua de Cicerón, "llamado vulgarmente Gramática y desempeñado por preceptores y dómines, fue general a todas las provincias (de la Península Ibérica)...", aunque debo recordar que faltaba, en esa centuria, en la generalidad de villas y lugares del Principado de Asturias, comenzando por la capital, donde

1 Sobre la biografía de este insigne asturiano, vid. por todos, González, J. L., (1968) El inquisidor general Fernando de Valdés: (1483-1568), dos vols., Oviedo, Universidad de Oviedo. 
solamente había clases no institucionales en los conventos de dominicos, benedictinos y franciscanos.

No obstante, cuando se trataba de crear la Universidad ovetense, -ya a principios del siglo XVII-, decía el Deán Asiego a los testamentarios del Arzobispo Valdés, que en la capital (asturiana) pasaban de 600 los estudiantes de latinidad, "materia que abandonaban después, por carecer de establecimiento donde completar la instrucción".

Fernando de Valdés, en palabras del antiguo rector de la Universidad de Oviedo (Canella Secades, 1985), mostró su especial manificencia con la erección del Estudio universitario ovetense, junto al Colegio de San Pelayo de Salamanca, y al colegio de Huérfanas Recoletas de Vetusta, “animado por los excelentes resultados que diera el Colegio de San Gregorio, que había establecido para el estudio de Gramática y Humanidades".

Creada la institución universitaria en Oviedo, los albaceas testamentarios del fundador, con respaldo del patrono colegial, que era un cognado próximo, redactaron, con autorización regia, unos estatutos, aprobados por el Consejo Real de Castilla el 12 de septiembre de 1612, en los que se previno la confirmación del número 12 de colegiales-becarios, ya inicialmente prevista por Valdés Salas en 1561, además de exigir para su ingreso que tuvieran entre siete y catorce años de edad, sin olvidar que fueran naturales del Principado de Asturias o parientes del fundador, cristianos viejos y de buen linaje. Como las lecciones eran públicas, acudían a sus clases muchos estudiantes externos, para aprender la Gramática o Lengua Latina, quienes recibían la enseñanza de forma gratuita (Canella Secades, 1985).

Entre el personal que servía plenamente el cumplimiento de la finalidad educativa prevista se mencionan, juntamente con dos fámulos, un cocinero, una lavandera y otros ministros, juntamente con un rector, ordenado in sacris, un regente, y un repetidor, todos los cuales, incluyendo los becarios que residían en el edificio colegial, eran nombrados por el patrono laical ${ }^{2}$. Entre los ministros hay que recordar al famoso jesuita P. Luis Alfonso de Carballo, nacido en 1571 y falle-

2 Sobre los nombramientos de los colegiales, que se conservaban en el archivo madrileño de la casa-palacio de Liría del Duque de Alba, último patrono del colegio, debemos recordar que se destruyeron en su generalidad a causa de un incendio, a finales del siglo XIX. El resto de expedientes, propiedad de D. Luis Arias, se conservan actualmente, gracias a una generosa donación, en el Archivo de la Universidad de Oviedo. Su transcripción, vid. GARCÍA SÁNCHEZ, J., Notas sobre la provisión de las becas del Colegio de San Gregorio de Oviedo durante el siglo XVII, BIDEA 116 (1935) 947-964; id., , Oviedo 1987. 
cido el año 1635, autor de las Antigüedades de Asturias, que desempeñó los oficios de preceptor y rector, antes de ingresar en la Compañía de Jesús (Penzol, 1958).

Aunque inicialmente el fundador encomendó la tutela del colegio al cabildo catedralicio ovetense, surgieron diversas disputas entre sus capitulares respecto de las obligaciones que le competían, reservándose finalmente para el patrono, con la supervisión del Consejo de Castilla. Se mantuvo la premisa, para acceder a una de las becas vacantes, que el aspirante fuera "pobre", para que por falta de maestros no dejara de comenzar y seguir ejercicios de virtud, y que no fuera vecino de Oviedo. Sin embargo, a lo largo del siglo XVII, con intensificación de la característica en el Siglo de la Ilustración, el colegio de San Gregorio se convirtió en "nobilísimo", porque sus becarios eran hijosdalgo notorios "de sangre y solar conocido, nobles principales", pertenecientes en su mayoría a las familias más influyentes de los concejos del Sur-Occidente asturiano, cuyos parentescos cognaticios con el fundador, a través del apellido Valdés o de otros derivados de afinidad, en muchos casos, era uno de los timbres de honor más relevantes, a la hora de decidir su incorporación en dicha casa-colegio ${ }^{3}$.

Antes de la fundación valdesiana, los dominicos, que llegaron a Oviedo merced al obispo Diego de Muros, impartieron lecciones de Latín a los aspirantes a clérigos, en su finca de San Pedro Mestallón, extramuros de la localidad, desde 1518. No prosperó el colegio que dicho prelado anejó a la capilla del Rey Casto en la catedral asturiana, mientras que la docencia impartida por los jesuitas, merced al mecenazgo que recibieron de doña Magdalena de Ulloa y su asentamiento en la capital asturiana, a partir de 1578, incluyó exclusivamente, de manera estable, permanente y gratuita, las clases de leer, escribir y contar, a quien quisiera acudir a sus aulas desde cualquier lugar del Principado de Asturias, si bien con patronazgo municipal, mediante dos ludi magistri, sin olvidar la enseñanza de la doctrina cristiana. No se extendió entonces, a pesar de que en las escrituras notariales se dejó abierta esta posibilidad, a la impartición de clases de Gramática (García Sánchez, 1992), e incluso a causa de la presencia de un seminario en el propio colegio jesuítico de San Matías permite entender que pudo desarrollar este objetivo docente hasta 1593, en cuyo año, por la peste y otras circunstancias

3 Baste referir algunas preguntas de dicho interrogatorio: "Dicho pretendiente ni sus padres, abuelos ni ascendientes jamas usaron ni exercieron oficio de los que el uso o derecho tiene o reputa por viles o mecánicos, antes si sabe usaron y exercercieron y exercen los mas principales y honrrosos como son los de rejidores perpetuos alguaciles juezes de hijos de algo y los demás que le Reppublica distribuye entre personas nobles y de la primera calidad"... es beneméritos de qualesquiera de los principales de su concejo y jurisdicción...". 
de la provincia a la que pertenecía dicha comunidad de religiosos, además de una queja formal de los prebendados de la catedral, se extinguió temporalmente ese ministerio.

No parece que impartiera inicialmente clases de Lengua Latina el colegio de San Pedro de los Verdes, dotado por el canónigo Pedro Suárez, que funcionó en Oviedo desde 1592, ya que estaba orientado a la formación teológica, con vida colegial de sus becarios, quienes completaban su formación en las aulas universitarias, una vez fue inaugurada la vida académica del Estudio ovetense en 1608. También fue reducido el alcance del seminario fundado por el obispo Diego Aponte de Quiñones (Gonzalez Dávila, 1986), en la propia residencia episcopal, que obtuvo respaldo papal, con la bula de 10 de mayo de 1593, pero que no perduró más allá de su óbito (Risco, 1795) ${ }^{4}$.

En la relatio que este prelado ovetense transmite a Roma, en su visita ad limina del año 1594, manifiesta el alcance de algunas iniciativas personales en el ámbito docente, frecuentando cada día las disputas sobre casos de Moral y Sacramentos, con coloquios en los que intervenía el prelado, y recuerda que en el cuadrienio precedente distribuyó catorce jóvenes en otras tantas parroquias, donde enseñaban Gramática y el servicio de altar a los niños (González Novalín, 1986).

Cum haec provincia ignorantiae caligine laboret, his sex praecedentibus annis, primo duodecim, deinde quindecim, postremo decem et octo iuvenes bonae indolis huius dioecesis domi meae habitationis ex mensa mea alendos et in moribus et litteris per memetipsum instruendos recepi; et ad praesens habeo quo ignorantiae caliginem a cordibus fidelium propulsem.

Durante el siglo XVII, merced a la generosidad de otro capitular catedralicio, se erigió, en 1662, el colegio-seminario de San José, obra del canónigo Pedro Díaz Oseja, arcediano de Villaviciosa, que estuvo bajo patronato del cabildo hasta el siglo XX. En esta comunidad se impartían lecciones de Gramática (Hevia Ballina, 1979).

4 Sobre los nombramientos de los colegiales, que se conservaban en el archivo madrileño de la casa-palacio de Liría del Duque de Alba, último patrono del colegio, debemos recordar que se destruyeron en su generalidad a causa de un incendio, a finales del siglo XIX. El resto de expedientes, propiedad de D. Luis Arias, se conservan actualmente, gracias a una generosa donación, en el Archivo de la Universidad de Oviedo. Su transcripción, vid. GARCÍA SÁNCHEZ, J., Notas sobre la provisión de las becas del Colegio de San Gregorio de Oviedo durante el siglo XVII, BIDEA 116 (1935) 947-964; id., , Oviedo 1987. 
Las quiebras financieras que el colegio de San Gregorio sufrió en sus capitales, destinados a las retribuciones previstas para cubrir la actividad de sus cátedras, obligarían a diversas intervenciones, de los responsables interesados, a presentar memoriales y realizar otras gestiones ante el poder regio hispano, que se había servido reiteradamente de sus rentas por vía de los juros, habitualmente impagados, a lo largo del siglo XVII.

Esta problemática se vió agravada a causa de la competencia académica que debió soportar en ese nivel formativo, proveniente de las Escuelas de Gramática instituidas por el Excmo. Ayuntamiento de Oviedo en el Principado de Asturias, con respaldo del máximo órgano político del territorio. Con ese objetivo, el regimiento ovetense dotó tres cátedras de Latinidad, que fueron aprobadas por el Consejo de Castilla, con la financiación de un arbitrio sobre el vino, y que la corporación municipal puso en funcionamiento a cargo de los religiosos de la Compañía de Jesús, residentes en su colegio de San Matías, a partir de 1681, en virtud de un convenio, suscrito notarialmente.

La iniciativa para la nueva fundación de escuelas de Gramática partió de la Diputación del Principado, que era el órgano de gobierno asturiano entre Juntas generales, y en 1676, a la luz de la pérdida de vigor de las cátedras existentes en San Gregorio, decide acoger la propuesta del marqués de Camposagrado, argumentando los daños que "experimentaban sus hijos, que la relijion de la Compañía no enseñase la Gramatica en que tantas veces se había discurrido", valorando la grave repercusión que podría tener en la fundación del Arzobispo de Sevilla, y sin olvidar que merecía el máximo respeto dicho prelado, así como el patrono del colegio de San Gregorio, marqués de Mirallo y Baldunquillo (García Sánchez, 1992).

Un primer intento consistió en fusionar ambas enseñanzas, para que los colegiales de San Gregorio acudieran, como externos, a las clases de Lengua Latina que impartirían los jesuitas en San Matías, aunque esta iniciativa no prosperó, porque la Compañía de Jesús quiso mantener su plena independencia, creando un nuevo centro docente, abierto a todos los ciudadanos y financiado con fondos públicos, tal cual se pudo culminar con la facultad regia expedida el 28 de mayo de 1681 (García Sánchez, 1992).

5 Dichas enseñanzas de Gramática, por parte de los jesuitas, que se ganaron el máximo elogio de los asturianos, concluyeron el 2 de abril de 1767, con la expulsión de Carlos III, aunque se mantuvieron vigentes bajo supervisión de la Universidad de Oviedo, a causa del patronazgo municipal. 
Las dificultades permanentes de correcto funcionamiento en las enseñanzas impartidas por los preceptores del Colegio de San Gregorio no fueron obstáculo para que mantuviera becarios ilustres, algunos de los cuales alcanzarían Mitras en el Continente Americano, como uno de los Cienfuegos Argüelles, hermano del cardenal jesuita de los mismos apellidos, en Méjico y Venezuela (García Sánchez, 1992), o Lué y Riega, en Argentina (García Sánchez, 1992).

Sin embargo, la pérdida de relevancia y escasez de alumnos, durante el primer tercio del siglo XVIII, motivó al entonces rector de la institución colegial, capitular del cabildo catedralicio, a proponer formalmente al obispo de Oviedo y al patrono, aunque posteriormente elevaría la petición de respaldo al regimiento de la localidad, la conversión de las enseñanzas institucionales de la Lengua Latina por diez becas, que disfrutarían quienes acudían a las Aulas de las Facultades Mayores de la Universidad, igualmente fundada por el insigne salense Valdés, con predominio de los estudios de Teología, para la que se reservaban seis, distribuidas dos por cada escuela: tomista, escotista y jesuítica, pero también otras cuatro para juristas, dos para legistas y otras dos para canonistas.

Se trató de un proyecto personal del canónigo y catedrático del Estudio universitario, D. Ignacio Menéndez Valdés ${ }^{6}$, para cuya puesta en marcha obtuvo previamente los respaldos del patrono del colegio, Conde de Miranda - Duque de Peñaranda; del obispo ovetense Avello y Castrillón ${ }^{7}$, junto al otorgado por el nuevo prelado de la misma sede episcopal, Vázquez de Tablada, entonces

6 Nació en Oviedo, y fue bautizado en la parroquia de San Tirso el Real, el 19 de julio de 1702, falleciendo en la capital asturiana, el 25 de octubre de 1770. Se ordenó de presbítero en 1732 y obtuvo de Felipe IV su nombramiento como abad de Covadonga hasta 1760, regentando la cátedra de Sagrada Escritura en el Estudio ovetense. Fue rector de la Universidad de Oviedo durante los cursos 1749-1750 y 1750-1751. Desempeñó el rectorado del colegio de San Gregorio desde mediados de la tercera década de dicha centuria hasta su óbito, ayudándole en el desempeño de esta tarea su sobrino Juan Martínez Valdés, que le sucedió en el cargo, hasta la invasión de las tropas napoleónicas. GARCÍA SÁNCHEZ, La librería del colegio de San Gregorio de Oviedo, en la formación de Lué y Riega, en Studium Ovetense 40 (2012) 150-152.

7 Sirva como dato de referencia para acreditar que no pudo culminar el respaldo a este proyecto, la inscripción de su óbito en la parroquia de San Isidoro el Real: Archivo de la parroquia de San Isidoro. Oviedo. Libro 4 de defunciones, de 1741 a 1769, fols 26v-27r: El 29 de octubre de 1744 el Excmo. Sr. D. Juan Avello Castrillon fallecio en los palacios episcopales. Era natural de Luarca, concejo de Valdés, lectoral en esta santa iglesia, doctor en la Universidad, penitenciario en la iglesia de Santiago de Galicia, colegial maior en Salamanca, y últimamente obispo de esta ciudad. No testo porque le falta el habla en fuerza de un accidnte que le duro ocho días. Fue sepultado su fcadaver en la santa iglesia catedral el dia 30 de octubre no dejo aniversario que yo tenga memoria... Juan Antonio Martinez". Rubricado. 
presidente del Consejo de Castilla (González Novalín, 1986) ${ }^{8}$, y la persona jurídica municipal, a partir del informe favorable emitido por los regidores, que habían sido nombrados comisarios para este negocio por la corporación de munícipes, contra el cual se alzó el procurador general de los caballeros hijosdalgo de la ciudad de Oviedo y su consejo'.

Dada la trascendencia de dicha iniciativa, que buscaba cambiar el objetivo inicial previsto por el fundador Valdés Salas, aunque manteniendo el vínculo con la formación académica de los posibles becarios del colegio, fue preciso solicitar la aprobación de la Santa Sede, quien reclamó un informe previo favorable de la autoridad eclesiástica ovetense. Este trámite dio lugar al conocimiento del proyecto por parte del procurador general del Principado, que en aras del interés del común del vecindario ovetense y del territorio asturiano, se opuso radicalmente a esa iniciativa, personándose en el tribunal eclesiástico asturiano para que se suscitara un contradictorio. Ello hizo que se suscitara la disputa jurídica con un doble frente: por un lado, si el rector era persona legítima para instar el cambio; por otro, quién era la autoridad competente para autorizarlo, a saber, si el Consejo de Castilla, o el patrono del colegio de San Gregorio, o simplemente el responsable eclesiástico a nivel diocesano, quien debía suplicar la bula pontificia que lo ratificara.

8 Tampoco pudo asumir la defensa del proyecto presentado por el rector colegial, porque falleció en la ciudad de Toro, el 29 de diciembre de 1749, aunque si hubiera sobrevivido, probablemente contaba con elementos suficientes para obtener respaldo tanto del Consejo de Castilla como de la Congregación romana, pues estaba graduado en ambos Derechos por la Universidad complutense, regentando cátedras y fue oidor de la Real chancillería de Valladolid, hasta llegar en 1746 a la presidencia del Consejo de Castilla. Vid. RISCO, M., O. F. M., España Sagrada. Tomo XXXVIIII. De la Iglesia exenta de Oviedo..., Madrid 1795, pp. 188-189; González Novalín, J. L., Las visitas ad limina de los obispos de Oviedo..., Oviedo 1986, pp. 133-134, aunque fecha su óbito en 1747.

9 La destrucción del Archivo Histórico Diocesano, en el que se conservaba toda la documentación relativa a la actividad episcopal, incluyendo los autos provenientes de la jurisdicción eclesiástica, así como la del Regente de la Audiencia, que era la máxima autoridad política del territorio, además de corregidor de Oviedo, dificultan conocer este asunto en todos sus detalles, aunque podemos examinarlos en la parte sustancias del conflicto, merced a la apelación interpuesta por el procurador general, así como por el fiscal de la Audiencia ovetense, ante el Consejo de Castilla, en Madrid. AHN. Sección Consejos. Leg. 27000-2, exp. 5: “Corte y Obiedo. Año de 1749. Don Juan Albarez Labarejos Procurador General de los Cavalleros hijos Dalgo de la Ciudad de Obiedo y su consejo CON Don Ygnacio Menendez Valdexs Rector del Colexio de San Gregorio de dicha Ciudad, SOBRE el nuevo proyecto para los estudios de dicho Colexio. 2 piezas. Esta 70 folios. Otra 24. Relator", en blanco. "Secretario Rezo. Escribanía Granados". 
En este punto baste recordar que la ejecución de las disposiciones mortis causa que contenían obras pías implicaba necesariamente la intervención del prelado ovetense, conforme a la normativa aplicable. En esta cuestión, dicho planteamiento echa sus raíces en el Derecho romano sin duda alguna, si tenemos presente lo dispuesto en la Novela 131, de Justiniano, del año 545, porque en su cap. $9^{10}$ se determina que el fuero competente respecto de la ejecución de dicho testamento era el eclesiástico, y en el cap. $11^{11}$, se reitera esa jurisdicción episcopal, de tal modo que como tal fue asumido por la legislación canónica en

10 "Si en el nombre de Jesucristo, Dios grande y Salvador nuestro, hubiere alguien dejado una herencia o un legado, mandamos que lo que se dejó lo reciba la iglesia de la localidad, en que el testador hubiere tenido su domicilio. Mas si alguien hubiere instituido heredero a uno de los santos, o a él le hubiere dejado un legado, y no hubiere nombrado especialmente el lugar en que está la venerable casa, pero se hallaran en la misma localidad o ciudad muchos oratorios del mismo santo, désele lo que se dejó preferentemente a la casa que sea más pobre. Pero si no hay en la ciudad basílica del santo nombrado, mas se hallara en su territorio, désele a ella. Pero si ni en su territorio se halla tal casa, en este caso désele lo que se dejó a la iglesia de la ciudad, en que el testador hubiere tenido su domicilio".

11 "Si para redención de cautivos o para alimentod e pobres hubiere dejado alguien una herencia o un legado en bienes muebles o inmuebles, ya por una sola vez, ya como renta anual, cúmplase de todos modos también esto conforme a la voluntad del testador por aquellos a quienes se les mandó que lo hicieran. Mas si no hubiere dicho especialmente de qué modo deja esto a los pobres, mandamos que reciba aquellos bienes el santísimo obispo de la ciudad, en que el testador tuvo su domicilio, y los distribuya entre los pobres de aquella ciudad. Pero si se deja alguna cosa para la redención de cautivos, y el testador no hubiere dicho nominalmente por quién deba hacerse la redención de los cautivos, mandamos que también en este caso reciban los bienes dejados para esto el obispod e la localidad, y sus ecónomos, y ejecuten esta obra piadosa. Porque queremos que en todas las pías voluntades provean los santísimos obispos de las localidades para que todo se haga con arreglo a la voluntad del difunto, aunque especialmente se les haya prohibido por los testadores o los donantes que tengan en esto participación alguna. Mas si aquellos a quienes se les mandó hacer esto, requeridos una y dos veces por medio de personas públicas por el beatísimo obispo de la localidad o por los ecónomos de éste, hubieren diferido cumplir lo que se dispuso, mandamos que pierdan ellos todo el lucro que se les dejó por el que dispuso aquello, y reivindiquen los obispos de las localidades todos los bienes destinados, según se ha dicho, para todas las causas pías, con los frutos y los aumentos del tiempo intermedio y con el mencionado lucro, y ejecuten lo que el testador dispuso, teniendo entendido, que si lo desatendieren, darán por todo ello cuenta a Dios. Mas si el santísimo obispo de la localidad hubiere desatendido alguna de las cosas que se han dicho por nosotros, séale lícito a su santísimo metropolitano exigirlas todas ellas y ejecutarlas, y tenga licencia cualquier otra persona para promover tal cuestión, y procurar que de todos modos se ejecuten las causas pías". 
$X 3,26,3^{12}$ y $6^{13}$, así como la explicitó la doctrina bajome-dieval, aplicando la regla: "episcopus succedit in potestate exequendi testamenta in quibuscumque legatis haerede non adimplente voluntatem defuncti".

La ejecución episcopal de las últimas voluntades que contenían obras pías ${ }^{14}$ se acentuó durante la Baja Edad Media de manera progresiva, amparándose en la legislación romana del Bajo Imperio, porque algunas constituciones imperiales colocaban su cumplimiento bajo la vigilancia del obispo, como vemos en C. Iust. $1,3,28,1^{15}$, del emperador León, en el año 468, o la constitución de Justiniano, del año 530, C. Iust. 1, 3, 45 pr (Bussi, 1939) ${ }^{16}$.

En este aspecto, los prelados ovetenses, Avello y Vázquez de Tablada, al examinar cualquier iniciativa del rector de San Gregorio que afectaba al colegio, en razón de su carácter de obra pía, cumplieron fielmente con la regulación

12 Si infra annum a die monitionis non fit exsecutio testamenti per debentem exsequi, devolvitur exsecutio ad episcopum... "Te hortamur... quatenus infra annum... Quod si infra praedictum tempus aliqua perficere negligentia vel calliditate distulerit, ut sive in loco eo, quo constitutum fuerat, seu certe, si ibi non potest, et alibi placet ordinari, tecum implere neglexerit, tunc ter te aedificetur, et omnia per te loco ipsi venerabili sine diminutione qualibet assignentur. Sic enim et ante tremendum iudicem tuum sententiam remissionis effugies, et secundum piisimas leges dilatas defunctorum pias voluntates episcopali decens est studio adimpleri".

13 "Heredi non adimplenti iussa testatoris, ab episcopo interdicitur res a testatore relicta. Ex concilio Maguntino. "Si heredes iussa testatoris non adimpleverint, ab episcopo loci illius omnis res, quae eis relicta est, canonice interdicatur, cum fructibus et ceteris emolumentis, ut vota defuncti adimpleantur"..

14 Sobre la regulación de las causas pías, vid. por todos, F. a MOSTAZO, Tractatus de causis piis in genere et in specie libri VIII... opus quidem perutile non solum iudicibus, et visitatoribus ecclesiasticis, verum etiam secularibus, 2 vols., Lugduni 1717. Un caso singular sobre el régimen de las causas pías, vid. J. J. RUBIO RODRÍGUEZ, El favor iuris de las causas pias ante la integibilidad de la legitima en el Derecho común e hispano, en Apollinaris 66 (1989) 69-84.

15 “... vir reverendissimus episcopus illius civitatis, ex qua testator oritur, habeat facultatem exigendi, quod huius rei gratia fuerit derelictum, pium defuncti propositum sine ulla cunctatione ut convenit impleturus", añadiendo en el parágrafo 3: “. . vir reverendissimus episcopus civitatis eius, in qua idem testator defunctus est, itidem habeat legati seu fideicommissi petitionem defuncti propositum modis omnibus impleturus".

16 "Sancimus, si quis moriens piam dispositionem faciat vel institutionis modo vel per legatum vel per fideicommissum vel portis causa donationem vel per quemlibet alium legitimum modum, sive pro tempore episcopo curam iniunxerit, quo ea quae disposuerit impleantur, sive de hoc tacuerit, sive e contrario eum prohibuerit, necesse esse heredibus facere et implere omnimodo quae ordinata sunt: quod si sponte non faciunt, tum religiosissimi locorum episcopi de iis anquirant atque eos conveniant, ut omnia secundum defuncti voluntatem impleantur". 
jurídico-canónica ${ }^{17}$ y secular ${ }^{18}$ que convertía al prelado en el vigilante de las últimas voluntades, máxime cuando el contenido de las mismas estaba destinado a obras pías.

Este cometido fue causa de directos enfrentamientos entre patrono colegial, el regimiento ovetense y el prelado ${ }^{19}$, quien, en su calidad de responsable último de la ejecución de las obras pías ${ }^{20}$, una vez pasado el año desde el óbito del tes-

17 Según el Decreto de Graciano "pertinet ad episcopum testamenti defensio sive executio testamenti ut voluntas defuncti servetur", y la competencia exclusiva de la autoridad eclesiástica en los casos señalados vino expresada por canonistas relevantes como Juan Andrés y el abad panormitano Nicolás de Tudeschi. El papa Gregorio IX dispuso que en la ejecución de estos testamentos no era posible eliminar la intervención del obispo, ni siquiera en el supuesto de que expresamente la hubiera excluido el difunto, porque conforme a X $3,25,17$, el obispo puede obligar a los ejecutores testamentarios a cumplir con el deber que les incumbe. La intervención del obispo tiene carácter público, y se dirige a tutelar uno de los postulados de la honestas cristiana, que no puede ser rechazado por ningún particular. Cf. F. X. WERNZ, Ius Decretalium..., op. cit., t. III, pp. 289 y 297.

18 La doctrina del Ius Commune comprende reglas especiales respecto de las piae causae, bajo el concepto de lo que llaman privilegia. Además de la ejecución de las disposiciones. Se somete al control episcopal la conducta de los albaceas, pudiendo incluso obligar a una persona que acepte la tarea de commissarius. En cualquier caso, in utroque foro, se reconoce la competencia, incluso por parte de los poderes seculares, de la aplicación en esta materia del ius canonicum, tal como afirma Andrés Tiraqueau. Vid. H. COING, Derecho privado europeo, t. I. Derecho común más antiguo (1500-1800). Trad. de la ed. alemana y apostillas de A. Pérez Martín, Madrid 1996, pp. 746-750.

19 MARTA, G. A. Summa totius successionis legalis quatuor partibus complexa, Lugduni 1623, col. 1094, sienta el principio: "Episcopus est exequutor dispositionum ad pias causas", puesto que "episcopus est executor a lege datus et factus", tal como indican las fuentes jurídicas y la doctrina, dentro de la cual cita a Nicolás de Tudeschis, Corarrubias y Tiraqueau. COVARRUBIAS, D. A Ad titulum de testamentis op. cit., pp. 60-62, sostiene de manera tajante: "Episcopus circa executionem ultimarum voluntatum, potest ultimam voluntatem commutare, quoties intervenit causa, aut dubia dispositio. Potestas exequendi ultimas voluntates etiam ante annum aufertur ab executore, et transfertur in episcopum si ab episcopo bis monitus executor ultimam voluntatem exequi noluerit: quod quidem, maxime ex justa causa, sive in legatis piis, sive in profanis procedere". MOLANI, J. Liber de piis testamentis, op. cit., pp. 205-207, no duda en examinar: Episcopo quatenus competat executio ultimarum voluntarum, partiendo del Concilio de Trento, sess. 22. Este jurista también recuerda la doctrina de Covarrubias, según la cual los obispos pueden obligar a los ejecutores testamentarios, incluso dentro del año, al cumplimiento de la última voluntad, incluso si lo prohibiera el testador. "Non potest testator prohibere episcopo exequi ultimam voluntatem, negligentibus executoribus, et elapsa dilatione iuris", aunque "episcopos potius esse superintendentes piarum executionem quam executores", a causa de que tiene muchos oficios, y no puede atenderlos todos personalmente.

20 Así lo había dispuesto el Concilio de Trento, sess. 22, cap. 8 de reform. "episcopi, etiam tamquam sedis apostolicae delegati, in casibus a iure concessis omnium piarum dispositionum tam in ultima voluntate, quam inter vivos sint executores". A falta de disposición expresa del testador: "ex iuris dispositione Ordinarii sunt ejecutores nati piarum voluntatum, cui executores inferiores ita subordinantur, ut eius visitationi subsint et vigilantiae in finem urgendi impletionem piae voluntatis". Cf. Conciliorum oecumenicorum decreta, op. cit., p. 740. 
tador, tomó la iniciativa de verificar minuciosamente si entraba en la mente del fundador, como voluntad mortis causa de Valdés Salas, la permuta de las becas de Gramática por otras de Estudios mayores, reflexionando con asesoramiento de teólogos y expertos este negocio, como era su obligación, tal como reconoce Francisco Carpio: "Pias testatorum voluntates, negligentia, morte, vel impedimento executorum, et commissariorum pertinet ad episcopum, eas ad effectum perducere" $^{\prime 21}$.

El proceso judicial fue examinado inicialmente por la Real Audiencia del Principado de Asturias (Tuero Bertrand, 1979), con intervención de fiscal ejerciente en dicho órgano jurisdiccional, a instancias del procurador general del común ${ }^{22}$, que manifiesta su claro punto de vista, oponiéndose a dicha pretensión, a tenor del poder notarial que otorgó con dicha finalidad, mediante la siguiente representación, con la cual contradecía el acuerdo de la persona colegiada municipal, que respaldó la permuta proyectada de los estudios de Gramática, mediante la dotación de algunas becas para cursar en las Facultades mayores del Estudio universitario, y negando, a dicho representante del interés público local, cualquier legitimidad para instar actuaciones, opuestas a los acuerdos municipales adoptados en las sesiones, ante los diversos tribunales (AAO. Libro de actas municipales. Sign. A-70. Año 1749, fols. 37v-38r) ${ }^{23}$ :

21 Este jurista pone de relieve que este principio "aperte constat de jure canonico... quod etiam jure civili sancitum est, ex lege nulli $C$. de episcopis et clericis... et aliis juribus, necnon in jure regio id etiam ostenditur ex l. 5 titulo 10 Partita 6 in illis verbis: estonce el Obispo de aquel lugar, onde es natural el que fizo el testamento, o aquel en cuyo obispado oviere la mayor aprte de sus bienes, lo debe fazer cumplir, quam sententiam communi Doctorum sufragio receptissimam esse constat ex Baldo, Panormitano, Barbatia, Antonio, Hostiense, Ioanne Andrea...relatis a Tiraquello de privilegiis piae causae, privilegio 149, per totum, Bovadilla in Politica, lib. 2 cap. 17, numeros 104 et 105". CARPIO, F. De executoribus et commissariis testamentariis libri quatuor, Ursaone 1638, fols. 97v-111v, cap. XXI-XXII.

22 En el proyecto de ordenanzas del municipio ovetense, elaborado por el regidor Gabriel Cueto, y fechado en 1784, figura entre los oficios el procurador general, con la misión de defender las regalías de la ciudad. Era un cargo, personero y procurador general, que se nombraba mucho tiempo antes de 1598, y estaba regulado en las ordenanzas del Principado, como vemos en las de Lorenzo Santos de San Pedro en el siglo XVII. Su nombramiento estaba previsto en la Real provisión de 1 de septiembre de 1598, y de este negocio se informa a Felipe II en 1599. Además de ocuparse de asuntos seculares relevantes, como los que afectaban al aprovisionamiento de productos de primea necesidad y sus precios, el 19 de septiembre de 1601, la ciudad de Oviedo acuerda revisar las denuncias de los pobres parroquianos acerca de los excesos que cometían los curas de Vetusta y resto del Principado u obispado en razón de los funerales de los difuntos. AAO. Libros de Acuerdos. Sign. A-14, fol. 848r

23 Ayuntamiento ordinario de 11 de marzo de 1749: In marg. "Representación de el Procurador general sobre la comutazion que pretende D. Ignacio Valdes de los Estudios 
En la Ciudad de Oviedo a veinte y tres días de el mes de Abril de mil setezientos y quarenta y nueve años ante mi scribano de Camara y testigos parezio presente don Juan Consul Jove vezino de esta Ciudad y procurador general de ella (AHPA. Sección protocolos. Escribano: José de la Fuente. Año 1746. Sign.7727, fols. 194r-195r) ${ }^{24}$, y Dijo que por cuanto por el Yllustrisimo señor don Fernando de Baldes de buena memoria a benefizio y utilidad de los vecinos, asi de esta dicha Ciudad como de el Prinzipado erijio y fundo un Colejio para estudios de Gramatica situado para la manutención de los maestros que le abian de enseñar renta suficiente de cuio colejio es actual Rector don Ygnazio Baldes doctor de la Unibersidad de esta dicha Ciudad por nominazion del Eszelentisimo señor Conde de Miranda patrono actual que es de

\begin{abstract}
de el Collexio de San Gregorio. Por D. Juan Consul Jove procurador general desta ziudad se rrepresento como aviendo llegado a su noticia que el Dr. D. Ignacio Menendez Valdes recttor de el collejio de San Gregorio intentaba suprimir los estudios publicos de Gramática que en dicho collejio a veneficio comun se avian avierto por disposición y voluntad de el Excmo. señor D. Fernando de Valdes Arzobispo que a sido de Sevilla y fundador desta Universidad, y que para el efectto y conseguir bullas apostolicas ocurrio ante el señor Provisor para que se le recibiese información de las causales que expuso, y de lo que de ella resultase diese su ttestimonio: a lo qual avia hecho contradizion atendido al notable agravio, no solo estensivo// a esta ciudad y sus rregalias, sino al todo de el Principado, y que en vista de ella dicho señor Provisor, mando dar a unos y otros sumarias justificaciones de el conttenido de sus rrespectivos pedimientos, dirijido segun manifestava a ynformar de lo uno y otro al Yllustrisimo señor Ovispo deste ovispado, y por ello y estas justissimas rrazones dignas de la mayor defensa y esfuerzo, ponia en la consideración de la Ziudad para que en el caso y como protector de semejantes obras pias providenciase lo mas conveniente = en cuya vista (in marg. Aqquerdo) se acordo que el señor D. Joseph Requejo trajese la razón que hubiere en el asumpto a favor de la Ciudad".
\end{abstract}

24 Ayuntamiento ordinario de 11 de marzo de 1749: In marg. "Representación de el Procurador general sobre la comutazion que pretende D. Ignacio Valdes de los Estudios de el Collexio de San Gregorio. Por D. Juan Consul Jove procurador general desta ziudad se rrepresento como aviendo llegado a su noticia que el Dr. D. Ignacio Menendez Valdes recttor de el collejio de San Gregorio intentaba suprimir los estudios publicos de Gramática que en dicho collejio a veneficio comun se avian avierto por disposición y voluntad de el Excmo. señor D. Fernando de Valdes Arzobispo que a sido de Sevilla y fundador desta Universidad, y que para el efectto y conseguir bullas apostolicas ocurrio ante el señor Provisor para que se le recibiese información de las causales que expuso, y de lo que de ella resultase diese su ttestimonio: a lo qual avia hecho contradizion atendido al notable agravio, no solo estensivo// a esta ciudad y sus rregalias, sino al todo de el Principado, y que en vista de ella dicho señor Provisor, mando dar a unos y otros sumarias justificaciones de el conttenido de sus rrespectivos pedimientos, dirijido segun manifestava a ynformar de lo uno y otro al Yllustrisimo señor Ovispo deste ovispado, y por ello y estas justissimas rrazones dignas de la mayor defensa y esfuerzo, ponia en la consideración de la Ziudad para que en el caso y como protector de semejantes obras pias providenciase lo mas conveniente $=$ en cuya vista (in marg. Aqquerdo) se acordo que el señor D. Joseph Requejo trajese la razón que hubiere en el asumpto a favor de la Ciudad". 
dicho colejio el que dicho doctor don Ygnazio Baldes pretende resumir y quitar los estudios en el, y para ello dado en el Aiuntamiento que se zelebro hoy dia de la fecha por la Justicia y Regimiento de esta Ciudad y cierto proiecto a el, que el otorgante en cumplimiento de su obligazion y de su enpleo hizo las contradiziones correspondientes a fin de que se desestimase la pretensión de dicho doctor don Ygnazio Baldes por algunos de los bocales que concurrieron a el, se acordó que el otorgante zesase en las contradiziones y deligenzias que en el asumpto abia practicado ante el Juez Ecclesiastico de esta dicha ciudad por lo que apelo en dicho Aiuntamiento, por tanto y para mejorarla otorga que da todo su poder cumplido el que de derecho se rrequiere y es necesario a D. Joseph de la Viña procurador del numero de la Real Audiencia de esta dicha ciudad para que en su nombre y representando su persona ocurra ante los señores Regente y oidores Alcaldes maiores de ella y pida que el escribano de Aiuntamiento venga hazer relación de dicho Acuerdo y aga las demás deligencias judiciales y estrajudiziales que convenga y el otorgante haría presente siendo hoiga autos y sentencias ynterlucutorios y definitivas y con todas sus ynzidencias... hasta conseguir se rreboque dicho acuerdo en perjuicio de el bien común, asi lo otorgo y firmo dicho otorgante a quien doi fee conozco siendo testigos D. Miguel Fernandez Vallina, Gregorio Garcia y Santos de Argüelles vecinos de esta dicha ciudad... Ante mi, Manuel Rivero Moreno. Rubricado (AHN. Sección Consejos. Leg. 27000-2, exp. 5, fol. 1rv).

El regimiento ovetense asumió rápidamente la importancia del asunto, y uno de sus regidores más relevantes, Antonio de Antayo, solicitó que la materia fuese examinada monográficamente en una sesión municipal (AAO. Libro de actas municipales. Sign. A-70. Año 1749, fols. 43v-44r) ${ }^{25}$. Celebrada dicha reunión, y obtenido el respaldo del regimiento a favor del punto de vista del rector de San Gregorio, tuvo lugar la interposición del recurso de apelación ante la Real

25 Ayuntamiento ordinario de 18 de marzo de 1749. In marg. "Tocante a los estudios de San Gregorio. Diose parte de el proyectto de el Dr. D. Ignacio Menendez Valdes recttor de el collexio de San Gregorio en asumpto al yntento que tiene de subir a estudios mayores los de Gramatica de dicho collexio; y aviendose rrepresentado por el señor D. Joseph Requejo no le aver sido posible traer para este ayuntamiento// el ynforme y razón que se le tiene encomendado anttes de ahora tocante al asumpto, se acordo que uno y otro se traiga para el primer Ayuntamiento, en el que se acordara se comboque antte diem rrespecto a pedirlo asi el señor D. Antonio de Antayo". 
audiencia asturiana que realiza José de la Viña, en nombre de Juan de Pedrosa Rubio, regidor, que compartía el criterio opositor del defensor del interés común de los ovetenses, está fechado el día 24 de dicho mes y año (AHN. Sección Consejos. Leg. 27000-2, exp. 5, fol. 3rv ${ }^{26}$, mientras que la personación en nombre del procurador general se data el día 26 inmediato posterior. En respuesta a ambos escritos, los miembros del Acuerdo los admitieron, acordando en la misma fecha que dicho asunto fuese examinado por la segunda sala de dicha órgano jurisdiccional colegiado asturiano (AHN. Sección Consejos. Leg. 27000-2, exp. 5, fol. $2 \mathrm{rv})^{27}$.

26 “En la ciudad de Oviedo a veinte y tres días del mes de Abril año de mil setecientos quarenta y nueve, ante mi el escribano de Camara y testigos D. Juan de Pedrosa Rubio vezino y rexidor perpetuo de esta Ziudad Dijo que por quanto la Justicia y Reximiento de ella en el ayuntamiento del dia veinte y tres del presente mes en vista de ziertos papeles llamados proyectos presentados por el Dr. D. Ygnazio Menendez Valdes; a fin de extinguir los estudios de Granmatica que fundo el Yllustrisimo señor D. Fernando de Valdes (de buena memoria) acordaron algunos de los vocales de dicho ayuntamiento aprobando dichos proyectos: y que el Procurador General zesase en las dilijenzias y contradiziones que avia practicado; a benefizio del común y vecinos; de lo que aviendose apelado por dicho D. Juan: por tanto y para mejorar dicha apelazion, otorga que da todo su poder cumplido y el que en derecho sea necesario a D. Joseph de la Viña procurador del numero de la Real Audiencia para que en nombre y representando su propia persona ocurra ante los señores Rejente y oidores Alcaldes mayores de ella: y pida que el escribano de Ayuntamiento venga a hazer relación de dicho acuerdo y haga las mas dilixencias... asta conseguir se revoque dicho acuerdo; y que se mande que dicho Procurador sindico general prosiga en las contradiziones y dilijenzias que sean necesarias a costa de la ciudad y sus propios, asi lo otorgo y firmo... Ante mi, Manuel Rivero Moreno". Rubricado.

27 El escrito del procurador, interponiendo su apelación, insiste en el principal contenido de este documento: "Joseph de la Viña en nombre de D. Juan Consul Jobe procurador general sindico general de esta ciudad y en virtud de un poder, ante V. S. me presento en grado de apelazion de un acuerdo zelebrado por la Justizia y regimiento de ella y es el caso que notizioso my parte de que el doctor don Ygnazio Mrenendez Valdes Rector del colejio de San Gregorio de esta dicha Ziudad pretendía extinguir los estudios de Gramatica que a benefizio de todos los vecinos de ella y este Prinzipado doto el Yllustrisimo señor D. Fernando de Valdes de buena memoria, cumpliendo my parte con la obligazion de su enpleo puso la debida contradizion ante el Probisor y Juez eclesiástico de este obispado donde pendia la instancia lo que motivo a dicho D. Ygnazio a dar cierto proiecto, para que la ciudad aprobase su pretensión, sobre lo qual abiendose combocado a Aiuntamiento extraordinario apra el dia veinte y tres de el presente en el que junto los vocales de el por algunos se ympugno y contradijo la pretensión de dicho D. Ygnazio por perjudicial al común, por otros de dichos bocales contra todo derecho se pretendio que my parte zesase en dichas contradiziones y que se recojiesen las dilijenzias que ubiese obrado en el asunto y por otros aprobando solo dichos proyectos, no ynpugnaron que my parte siguiese su ynstanzia, en cuya confusión dicho my parte propuso en voz la apelazion de dichos botos sin embargo de ser la mayor parte por la que se botaba siguiese su ynstanzia, por conocer que la cualidad de la aprobazion de dicho proyecto que contenia y asimismo dichos botos, y que por ser la mayor parte se tubo por acuerdo, podía ser perjudicial a la ynstanzia que a benefizio de dicho común y vecinos sigue my parte y no siendo justo que con dichos acuerdos se de lugar a semejantes agravios me presento en dicho grado de apelazion, a V. S., pido y suplico me aya 
Ejecutando la anterior providencia del tribunal asturiano, José Melchor Menéndez, escribano de número y ayuntamiento, hizo la certificación, en presencia del comisario José Requejo Tineo, y con data 22 de marzo de 1749, que había sido solicitada por ambos litigantes, refiriendo en primer lugar la representación que el procurador general Juan Cónsul, y sobre todo el regidor José Requejo Tineo (AAO. Libro de actas municipales. Sign. A-70. Año 1749, fols. 46r-47v) ${ }^{28}$, hiciero ante los doce munícipes asistentes a la sesión celebrada el 11 de marzo de 1749:

por presentado y se sirva de mandar que el escribano de ayuntamiento venga azer relación de dicho acuerdo a la segunda y a ello un portero le apremie, y en su vista se sirva de revocarle por las razones que llebo dichas en quanto a la aprobazion de dichos proyectos y en todo lo demás que sea en perjuicio de dicho común y vecinos tomando en el asunto las providenzias que mas combengan que es Justicia... Juan Consul Jobe. Viña". Rubricados.

28 Ayuntamiento ordinario de 22 de marzo de 1749: In marg. "Ynforme en quanto a la pretension de D. Ignacio Valdes rector de el colleji9o de San Gregorio. Por el señor D. Joseph Requejo se a ttraydo a este Ayuntamiento el ynforme o razón que se le avia encargado en el de onze de el corriente tocante a la representación de el procurador general empunto de el yntento de el doctor D. Ignacio Valdes de comuttar a estudios mayores los de Gramatica de el collexio de San Gregorio cuyo ynforme dize asi. Haviendo vistto y reconocido el testamento del Yllustrisimo señor D. Fernando de Valdes que se halla en el archivo de este Ayuntamiento de el resulta la razon y fundación que dicho señor hizo en la Universidad de esta Ciudad y tener asimismo fundado el Colegio de san Gregorio, para colegiales y estudios de Gramatica y a espalda de dicho libro y a su conclusion de dicho testtamento se halla inserta una proposicion hecha por el doctor Condres Pumarino en este Ayuntamiento de cómo la administracion de dicho Colegio y enseñanza de la Gramatica a los estudiantes no se guardava lo dispuesto/ por la fundación de el señor Arzobispo de Sevilla por quanto a la enseñanza de los colegiales que asistian a dicho Colegio no se les asistia ni a los demas que acudian a estudiar la Gramática con el cuidado que se dispone por dicha fundacion y que no se cumplia con la voluntad del señor fundador y que seria vien que respecto la Ciudad le ymportava por el vien que de cumplirse resultava a los hixos de vezino y mas de el Principado y por tocar a la Ziudad por disposicion de el señor Arzobispo lo representase al patrono por ser materia tan ymportante al servizio de Dios, y util de todos y embista de dicha proposicion se nombrò por comisario a dicho señor con el señor Adelantado de la Florida para dar parte al patrono, y la fundacion de dicho estudio no se halla inserta en la copia de el referido testamento. Y asimismo con el motivo de la reserva de juros hecha por S. M. y falta quer hazian a la continuacion de Estudios en dicho Colegio pàreze se ha dado por el año de mil seiszientos y tantos por esta ciudad cavildo y Principado a S. M. memorial ympreso que de el a la lectura exivo copia sacada de un libro empergaminado de diferentes memoriales ympresos que tenia// fol. $47 \mathrm{r}$ un particular en su poder. $Y$ dichos estudios se an mantenido en dicho Colegio y por parte de la ziudad en el año de mil seiszientos y ochenta se ha pensado en fundar los del colegio de la Compañia de Jesus a expensas del pueblo para mejor alivio de sus vecinos. Y haviendo havido varios Ayuntamientos sobre lo referido, y tratadose sobre el asumpto con el Padre Recttor y Colegio de la Compañia de Jesus, se ajusto en dar ziento cuarenta ducados para la manutencion perpetua de dichos tres maestros y fabrica de los estudios, y haviendose ocurrido al Real y Supremo Consejo de Castilla a pedir su aprobación y facultad para cargarlo en el arbitrio del vino que se vendia por menor pareze segun resulta de dicha facultad salio contradiciendolo y a embarazar se fundasen dichos estudios la patrona que actualmente hera de dicho Colegio de San Gregorio, y controvertidose en Justizia con dicha señora y el Fiscal de S. M. sin embargo de las contradiziones pues todo se aprovò el referido aqquerdo, revajandose 
Haviendo llegado a su noticia que el Dr. D. Ygnacio Menendez Valdes Recttor de el Colegio de San Gregorio yntentava subprimir los estudios públicos de Gramattica, que en dicho Colegio a beneficio común se habían abierto por disposizion y voluntad de el Excelentisimo señor D. Fernando de Valdes, Arzobispo que ha sido de Sevilla, y fundador que fue de esta Unibersidad, y para el efecto y conseguir Bullas Apostolicas, ocurio ante el Probisor y Juez eclesiástico para que se le reciviese ynformazion de las causales, que espuso, y de lo que de ella resultase diese su testimonial, a lo qual havia hecho contradicion atendido el notable agravio no solo estensible a esta Ciudad, y sus regalías, sino a todo del Prinzipado, y que em bistta de ella el zittado Provisor, mandó dar, a unos y otros, sumarias justtificaziones del contenido de sus respectivos pedimentos, dirigido según manifesttava, a informar de lo uno y otro al Yllustrisimo señor obispo de estte obispado, lo qual y las justísimas razones dignas de la mayor defensa y esfuerzo, ponía en la considerazion de la Ciudad para que en el caso, y como prottecttor de semejantes obras pias providenciase lo mas conveniente. $\mathrm{Y}$ em bistta de esta representación se acordó que D. Joseph Requejo (AHPA. Sección protocolos. Escribano: José de la Fuente. Año 1746. Sign.7727, fols. 36r-37r $)^{29}$ llevase

a sesenta ducados para la manutención de los Padres, y dos mil para la fabrica de la obra de dichos estudios, y es lo que resulta de los libros de ayuntamiento/ Real Facultad y testamento que reconocí con asistencia del presente scrivano y es lo que puedo ynformar a V. S. Oviedo y marzo veinte y dos de mil setecientos cuarenta y nuebe. Joseph Requejo Tineo".

29 De las actuaciones de este comisionado, sirva como referencia AHPA. Sección protocolos. Escribano: José de la Fuente. Año 1746. Sign.7727, fols. 36r-37r: "Pôder para pleito. Año de 1728. en la ciudad de Oviedo a veinte y un dias de el mes de junio de mill sdetezientos $\mathrm{y}$ veinte y ocho años ante mi escribano y testigos D. Joseph Requexo Tineo vezino y rexidor perpetuo desta ciudad y procurador general de ella $=$ Dixo que por quanto como tal Procurador general ha litigado y esta litigando diferentes pleitos pertenecientes a los señores Justicia y Regimiento desta dicha Ciudad, y en defensa de sus regalias propios y rentas y en benefizio de el comun con la mayor aplicación, cuidado y desvelo que corresponde a empleo de tal procurador general, y en que se han ofrecido algunos gastos que constan en Memorial, que por el otorgante se ha dado a dichos señores Justicia y Regimiento quien ha mandado pagarlos a su mayordomo de propios, como los pago y asimismo dichos señores Justicia y Regimiento en conocimiento de todo lo obrado por el otorgante en el Ayuntamiento hordinario, que celebraron el dia diez y seis de el presente mes fueron servidos acordar se le diese por via de remuneración mil reales de vellon y que por ellos se despachase libranza sobre dicho mayordomo cuio acuerdo y libramiento solo se contradixo por D. Juan de Pedrosa Rubio uno de los rexidores de dicho Ayuntamiento y actualmente juez hordinario desta ciudad sin mas pretesto causa ni motivo justo que para ello tubiese, sino es el ver y saber que el otorgante como tal procurador general en defensa de las regalias de dichos señores Justicia y regimiento/ ha litigado y litiga diferentes pleitos en el Real y Supremo Consexo de Castilla como en la Real Audiencia desta Ciudad sobre que los 
la razon que en el/ asumpto huviere a favor de la Ziudad, lo que hizo y ejecutto asi, de que se dio quenta en el Ayuntamiento, celebrado por dicha Justticia y Rejimiento en veinte y dos del zittado mes de Marzo.

Para evacuar el informe, dicho comisionado tomó como primer referente el testamento del Inquisidor General Fernando de Valdés, del cual se conserva una copia en el archivo municipal (AAO. Sign. C-8, fols. 1r-42r. Copia de 1642), con las últimas anotaciones de un antiguo regidor, catedrático de prima de Leyes en la Universidad de Oviedo, durante la primera mitad del siglo XVII:

Haviendo bistto y reconocido el testamento del Yllustrisimo señor D.
Fernando de Valdes, que se halla en el Archivo de este Ayuntamiento
de el resulta la razón y fundazion que dicho señor hizo en la Uniber-
sidad de estta Ciudad, y tener asimismo fundado el Colegio de San
Gregorio, para colegiales y estudios de Gramatica, y a espalde de di-
cho libro y a su conclusión de dicho testtamento se halla inserta una

señores Rexente y oidores alcaldes mayores de ella no les perturbe a dichos eñores, Justicia y Reximie3nto, dichas regalias. Y en consequenzia de lo referido, dicho señor D. Juan de Pedrosa Rubio en virtud de ser contador de dicha Real Audiencia nombrado por ella, y en prosecución de su contradizion contra lo votado y acordado por el Ayuntamiento pleno, se presentô en grado de apellazion ante dichos señores Rexente y Oydores alcaldes mayores aonde se llevo dicho acuerdo y fue revocado en contra de el estilo y costumbre inoncusa de las regalias de la Ciudad y Real Zedula de su Majestad (Dios le guarde) en que ordena y manda se este a lo acordado por mayor parte de votos y lo que es mas sin averse zitado en razon de dicha apellazion al ototgante ni oydole, ni dadole lugar a representar las causas justas que tenia para ver y percibir dichos mill reales, los que asistieron y asisten a dichos señores Justicia y Regimiento para librarselos, cuia revocación al otorgante le ha sido y es muy perjudicial, y mucho mas por contener la palabra de sin embargo cortando al otorgante el recurso de la suplica a dicha Real audiencia. Por tanto, y no ser justo se execute con el otorgante lo referido a vista de que dichos señores Justicia y Regimiento siempre tubieron la libre facultad de remunerar, como remuneraron a sus procuradores generales la aplicación y cuidado a las cosas y pleitos de la ciudad y utkilidad de el publico y con mayores cantidades para que se represente asi a s. M. señores de su Real y Supremo Consexo de Castilla y pedir el que se sirvan mandar aprobar y confirmar el referido acuerdo y que dicha Real Audiencia para en adelante cumpla, guarde y observe lo resuelto y mandado por S. M. en su Real Zedula de veinte y siete de octubre del año proximo pasado de setecientos y veinte y siete presentandose en caso necesario en grado de appellazion y como mas combenga a los procedimientos de dicha Real audiencia y pidiendo se libren los Reales despachos sobre el caso necesarios, otorga que da todo su poder cumplido el que se requiere y es necesario a D. Juan Fuertes vezino de la villa de Madrid, para que en nombre de el otorgante y representando su propia persona en dicha razon pueda hazer y haga todas las diligencias judiciales y extrajudiciales que convengan y sean necesarias... siendo testigos D. Pedro de Toro Escaxadillo D. Joseph de Granda Toro y Manuel Diaz vecinos de esta Ciudad = Joseph Requexo Tineo. Ante my, Joseph de la Fuentte". Rubricados. 
proposizion hecha por el doctor Condres Pumarino ${ }^{30}$, en este Ayuntamiento, de como la Administrazion de dicho Colegio y enseñanza de la Gramattica a los estudiantes, no se guardava lo dispuesto por la fundazion de el señor Arzobispo de Sevilla, por quanto a la enseñanza de los Colegiales que asistían a dicho Colegio no se les asistia ni a los demás que acudían a estudiar la Gramattica con el cuidado que se dispone por dicha fundazion, y que no se cumplia con la voluntad de el señor fundador, y que seria bien que respecto a la Ciudad le ymporttava por el bien que de cumplirse resultaba a los hijos de vecinos, y mas de el Prinzipado, y por tocar a la Ciudad por disposizion de el señor Arzobispo, lo representase al patrono, por ser materia tan importante al servicio de Dios, y útil de todos, y embista de dicha proposizion se nombró por comisario a dicho doctor con el Adelantado de la Florida para dar parte al patrono, y la fundazion de dicho Estudio no se halla inserta en la copia del referido testamento ${ }^{31}$.

El problema más grave para el funcionamiento del Colegio de San Gregorio, tal como lo instituyó el Arzobispo de Sevilla, era la falta de estudiantes a causa de la sólida y rigurosa formación que recibían también en Gramática a través de unos religiosos residentes en el Colegio jesuítico de San Matías, fundado en Oviedo por doña Magdalena de Ulloa, en el último tercio del siglo XVI, aunque era patrono el arzobispo de Granada, Martín Carrillo de Alderete (Grarcía Sánchez, 1992).

Por este motivo, en dicha representación era imprescindible aludir a las clases de Gramática, además de las de Primeras Letras, impartidas por los jesuitas en la capital del Principado de Asturias (Grarcía Sánchez, 1992).

Dichos estudios se han mantenido en dicho Colegio (de San Gregorio), y por parte de la Ciudad, en el año de mil seiscientos y ochenta, se ha pensado en fundar los de el Colejio de la Compañía de Jesus a espensas de el pueblo, para mejor alivio de sus vecinos y habiendo habido barios Ayuntamientos, sobre lo referido y tratadose sobre el asumpto

30 Fue catedrático de Prima de Leyes en la Universidad de Oviedo, además de regidor del ayuntamiento ovetense, que falleció a mediados del siglo XVII.

31 "Y asimismo con el motivo de la reserva de juros, hecha por S. M. y falta que hacían a la continuación de estudios en dicho Colegio, parece se ha dado por el año de mil seiszientos y tantos, por esta Ciudad, Cavildo y Principado memorial impreso a S. M. que de el, a la letra, exivio copia, sacado// de un libro empergaminado de diferentes memoriales impresos, que tenia un particular en su poder". 
con el Padre Recttor y Colegio de la Compañía de Jesus, se hajustó en dar cattorze mil ducados para la manutenzion perpetua de dichos tres maestros, y fabrica de los estudios. Y haviendose ocurrido al Real y Supremo Consejo de Castilla, a pedir su aprovazion y facultad para cargarlo en el arbitrio del vino, que se vendia por menor, parece según resulta de dicha facultad, salio contradiciéndole y a embarazar se fundasen dichos Estudios la patrona que actualmente hera de dicho Colegio de San Gregorio (la condesa de Miranda), y controbertidose en Justicia con la susodicha, y el Fiscal de S. M., sin embargo de las contradiziones puestas, se aprobó el referido acuerdo rebajando a seis mil ducados para la manutenzion de los Padres, y dos mil, para la fabrica de la obra de dichos estudios (Grarcía Sánchez, 1991) 32 .

El memorial impreso que se elevó al Rey, sin declarar la fecha ni el destinatario concreto, estaba suscrito por el cabildo de la catedral de Oviedo, el regimiento ovetense, el Principado de Asturias y la misma Universidad asturiana, junto con las propias “Escuelas menores de ella, fundazion de el Reverendo Padre D. Fernando de Valdes, Arzobispo de Sevilla, Ynquisidor de la Suprema, Presidente de Castilla, y Governador de estos Reynos" (AAO. Libro de actas municipales. Sign. A-70. Año 1749 , fols. $52 \mathrm{v}-54 \mathrm{v})^{33}$.

32 La alta especialización de los jesuitas por la enseñanza de la Gramática, amparada desde las primeras décadas de su vida institucional, queda reflejada en los elogios que San Francisco de Borja dirige en 1567 al P. Juan Bonifacio, residente en Ávila, a través de una carta que envía al provincial: "Muy importante que se favorezca el ministerio de leer gramatica y se agradezca con palabras y lo que más se ofreciere a los que se dedican de buena voluntad para este officio". Por otra parte, en la información que precedió a la escritura de concierto entre la ciudad de Oviedo y el colegio de San Matías, el rector de este último expresa nítidamente la utilidad de los estudios de Gramática, mostrando el sumo gusto y prontitud con que los incorporarían al colegio, además de lamentar que no pueden hacer frente al gasto que ello supone, a causa de la cortedad de su hacienda, incluso insuficiente para los alimentos de los estudiantes de la Compañía. Los únicos problemas que soportó esta fundación fueron los derivados del cobro del arbitrio municipal asignado para su mantenimiento, lo que provoca continuas reclamaciones durante los primeros años del siglo XVIII.

33 “Y porque por olbido se pasò ynsertar a continuacion de el ynforme de dicho señor D. Joseph de Requejo el memorial ympreso que expresa averse dado a S. M. se pone aquí y es como se sigue = In marg. Memorial dado a s. M. sobre los estudios de San Gregorio que refiere en su ynforme el señor Requejo. La Santa iglesia Cathedral de la ziudad de Oviedo la misma ziudad el Principado de Asturias y la Univesidad sita en dicha Ciudad, y la escuelas menores de ella, fundación de el Reverendo padre D. Fernando de Valdes Arzobispo de Sevilla inquisidor de la suprema Presidente de Castilla, y Governador de estos Reynos, dicen que atendiendo dicho señor Arzobispo con afecto paterno, la falta de doctrina que havia en aquellas montañas// fol. 53r y 
Las motivaciones para elevar la súplica, dirigida a la financiación de las obras pías que dejó en Oviedo el ilustre salense, permite a las instituciones asturianas presentar las raíces de las mismas y la finalidad pretendida por el fundador:

con animo de desterrar la ignorancia que en ellas havia fundò dicha Universidad de todas ciencias que son escuelas mayores y juntamente escuelas menores, con titulo de colegio de San Gregorio prinzipiop necesario y preziso para las scienzias mayores, donde quatro maestros leen cada dia, cada uno quatro lecciones, y por ser obra tan santa para aquella Ciudad y principado y provincias zircunvezinas como son las montañas de Leon, Burgos y Galicia, las Santidades de Pablo cuarto y Gregorio dezimo terzio confirmaron dichas fundaciones por sus Bullas, y los Reyes, progenitores de v. M. las rezivieron devajo de su protección y amparo como consta de sus Reales Zedulas = Luego despues de su fundación se experimentò la gran utilidad que se siguió a todo el Principado y provincias, pues an salido y salen cada dia hombres tan doctos, que sirven a Dios, a V. M. y a la Iglesia en cátedras, en iglesias, ploazas y colegios y en curatos, pues los curas de las parroquias de aquel Principado son los mas capazes para en su ofizio que ay en todo el Reyno $=$ Pero/ por tener dicha Universidad escuelas mayores, y dicho colegiod e San Gregorio escuelas menores, toda su renta en juros antiguos, y por haverse valido V. M. de las medias annatas, vinieron a tan miserable estado que no havia Doctores, ni Maestros que las quisiesen servir, de modo que se zerraron las puertas a no haver V. M. el año pasado acudido a su remedio con su liveral mano reservandoles sus juros perpetuamente reduziendo9los a los quatro Generos, que gozan de la universal reserva $=Y$ siendo asi que la reserva de los juros de dicha Universidad se devia entender (mediante la voluntad de V. M. de los juros de dichas Escuelas mayores y menores, por no lo expresar el Memorial tan solamente tubo efectto con las Escuelas mayores, quedando las menores sin esta merced y sin remedio, pues toda su renta consiste en juros de seiscientos cuarenta y tres mil nuebezientos ochenta y seis maravedis. Renta vien tenua para tanto trabajo y tanto numero de criados, que viendose destituidos de sus rentas tratan de dexar sus cátedras, por no tener, con que se substentar, y por la misma razón ningun otro se quiere oponer y asi dicha Ciudad y principado Universidad y Colegio humildemente suplican a V. M. se sirva mandar declarar que dicha gracia y merced que hizo a la Universidad// 54r y escuelas mayores se entienda de todo el cuerpo estendiendose a las menores y Colegio de San Gregorio) (sic) mandando corran los despachos generalmente por dichas Universidad y Colegio = Lo primero porque el prinzipio originario para llegar al conocimiento de las zienzias es Lengua latina que en el se enseña sin la qual no se pueden conseguir dichas scienzias $=$ Lo otro porque dicho Colegio es miembro lejitimo de dicha Universidad y prinzipio de ella; por enseñarse en el los primeros rudimentos a la juventud, y es zierto no estubiera ni fuera perfectta dicha Universidad de todos los requisitos, con que la dexo adornada su fundador y aprovada por la Sede apostolica y por los señores reyes de Hespaña progenitores de V. M. si le faltara a dicho Colegio y su conservación por ser Escuelas menores de ella que son como pies de un cuerpo natural = Lo otro porque por ser tierra tan pobre es ymposible los naturales enviar a sus hijos a estudiar fuera del Principado, y en el, no haver otro seminariod e letras, y si este faltase quedavan los naturales/ sin remedio sepultados en la misma ignorancia $=$ Lo otro porque V. S. imitando a Dios nuestro señor y a sus obras no puede ni debe hazer cosa ynperfecta, ni debe permitirla. Lo otro, porque dicho Colegio y Universidad estan fundados en dicho Principado de Asturias que es el primitivo señorio y dominio de V. M. y de los señores Reyes de España, sus progenitores, y de derecho natural, debe atender a la primera felicidad, pues ella fue prinzipio de las subsecuentes, como loo fue dicho Principado en la feliz y gloriosa restauración de España = Lo otro, porque el concurso de estudiantes a dicha Universidad ha pasado de mil y quinientos y no es justo se malogren tantos y tan buenos yngenios por no terner maestros ni cátedras, en que perfeczionar sus yngenios = En lo asi mandar hacer Dios nuestro Señor se darà por mui servido y los vasallos reziviran la merced limosna y amparo, que esperan de la Real liveral y piadosa mano de v. M. que Dios guarde". 
Atendiendo dicho señor Arzobispo con afecto patterno, la falta de Docttrina, que havia en aquellas Montañas (de Asturias), y con animo de desterrar la ignorancia que en ellas havia, fundò dicha Unibersidad de todas sciencias que son Escuelas mayores, y juntamente Escuelas menores, con tittulo de Colegio de San Gregorio, principio necesario y preciso para las sciencias maiores, donde quatro Maestros, leen, cada dia cada uno quatro leeziones, y por ser obra tan santa, para aquella Ciudad y Principado, y provincias zircunbezinas como son las montañas de Leon, Burgos y Galicia, las Santtidades de Pablo quartto ${ }^{34}$, y Gregorio decimo terzio ${ }^{35}$, confirmaron dichas fundaziones por sus Bullas, y los Reyes, projenitores de vuestra Magestad las recibieron debajo de su protección y amparo, como consta de sus Reales Zedulas.

Luego despues de su fundazion se experimento la gran utilidad que se siguió a todo el Prinzipado y Provincias, pues han salido y salen cada dia hombres tan docttos, que sirven a Dios, a V. M. y a la Yglesia, en cathedras, en yglesias, plazas y colegios, y en curatos, pues los curas de las parroquias de aquel Principado son los mas capaces para en su oficio que ay en todo el Reyno ${ }^{36}$.

34 Las primeras fundaciones de los dos colegios, San Gregorio en Oviedo y San Pelayo en Salamanca, cuyas escrituras notariales primigenias son de 1557 y 1556, respectivamente, debieron dar origen a unas bulas emanadas durante el pontificado de Paulo IV, aunque no las hemos podido verificar.

35 La erección de la Universidad y colegios por el Papa Gregorio XIII tuvo lugar en 1574. Afortunadamente pudimos localizar la súplica de los testamentarios de Valdés Salas, así como integrar el texto de la bula pontificia.

36 "Pero por tener dicha Unibersidad escuelas maiores, y dicho Colegio de San Gregorio escuelas menores, toda su renta en juros antiguos, y por haverse balido V. M. de las medias anattas, vinieron a tan miserable estado que no havia docttores, ni maestros que las quisiesen servir, de modo que se zerraron las puertas, ha no haver V. M. el año pasado acudido a su remedio con su liberal mano reservándoles sus juros perpetuamente reduciéndolos a los quatro generos que gozan de la Universal reserva $=\mathrm{Y}$ siendo asi que la reserva de los juros de dicha Universidad se devia entender (mediante la voluntad de V. M.) (sic) de los juros de dichas escuelas, maiores y menores, por no lo expresar el Memorial, tan tolamente tubo efecto en las escuelas mayores, quedando las menores sin esta merced, y sin remedio, pues toda su renta consiste en juros, de seiscientos quarenta y tres mil nuebezientos ochenta y seis maravedís de renta bien tenue para tanto trabajo, y tanto numero de criados que viéndose destituidos de sus rentes, tratan de dejar sus cathedras, por no tener con que substentar, y por la misma razon, ningún otro se quiere obponer, y asi dicha Ziudad y Prinzipado, Universidad y Colegio humildemente suplican a V. M. se sirva mandar declarar que dicha gracia y merced que hizo a la Unibersidad, y escuelas 
Al desarrollar los argumentos que servirían ante el Rey para lograr que se equiparasen las Escuelas mayores de la Universidad de Oviedo, donde se enseñaba Artes, Teología, Leyes y Cánones, con las Escuelas menores del Colegio de San Gregorio, los solicitantes pasan a especificar aquellos aspectos más relevantes:

Dicho Colegio es miembro lejitimo de dicha Universidad y Prinzipado de ella, por enseñarse en el los primeros rudimentos a la juventud, y es cierto no estuviera ni fuera perfectta dicha Universidad, de todos los requisitos, con que la dejó adornada su fundador y aprobada por la Sede Apostolica, por los señores Reyes de Spaña progenitores de V. M. si le faltara dicho Colegio y su conservazion por ser Escuelas menores de ella, que son como pies de un cuerpo natural.

Lo otro, porque por ser tierra tan pobre es imposible (a) los naturales embiar a sus hijos a estudiar fuera de el Principado, y en el no haver otro seminario de Lettras, y si este faltase quedavan los naturales sin remedio sepultados en la misma ignorancia.

Lo otro porque V. M. imitando a Dios Nuestro Señor y a sus obras, no puede ni debe hacer cosa ynperfectta ni debe permitirla.

Lo otro porque dicho Colegio y Unibersidad están fundados en dicho Prinzipado de Asturias, que es el primitivo señorio y dominio de V. M. y de los señores Reyes de Hespaña, sus progenitores, y de Derecho natural debe atender a la primera felicidad, pues ella fue principio de las subsequentes, como lo fue dicho Prinzipado en la feliz y gloriosa restaurazion de España.

Lo otro, porque el concurso de estudiantes a dicha Unibersidad ha pasado de mil y quinientos y no es justo se malogren tantos y buenos ingenios, por no tener Maestros, ni Catedras, en que perficionar sus yngenios

Si los fundamentos descritos podían mover al Rey Felipe IV, para darle la protección análoga al Colegio y Universidad, el rector del primero, que

maiores, se entienda de todo el Cuerpo, entendiéndose a las menores, (Colegio de San Gregorio) (sic), mandando corran los despachos generalmente para dichas Universidad y Colegio". 
desempeñaba su tarea desde 1736, hizo un proyecto totalmente novedoso, que presentó en el Ayuntamiento de Oviedo, para transformar la institución de Escuelas menores en una parte de Escuelas mayores, suprimiendo en el colegio la enseñanza de Gramática ${ }^{37}$ :

D. Ygnacio Menendez Valdes, que logra el honor de ser hixo, aunque el menor, de esta ciudad nobilissima: haze la mas rendida y filial representación en que habla a V. S. como hixo, y no como Recttor del Nobilisimo colegio de San Gregorio, para mas bien acreditar su amor y veneración.

Como la voluntad, que es fina, suele por querer adelantarse, tropezar en si propia, subcedio a la mia estta desgracia; pues quando amante agradecido hijo de V. S. havia pensado, en obsequio de Dios Nuestro Señor, de V. S., del bien común y de los Pobres, haver hallado el medio mas seguro de acreditar estte deseo en subir a maiores estudios el Colegio de San Gregorio de esta Ciudad, erre el camino, sirviendome de tropiezo, el poderoso brazo de V. S. a quien havia pensado hacer el mayor culto.

Pero si errè, señor, fue con tan buen deseo de azertar y con tan buenas cartas, que no las quiero mas recomendables para el logro de el mayor negocio, que es el de mi Salvazion.

Si yo en el adelantamiento de este Colegio, de el común, y bien publico, he trabajado algo, lo podrá juzgar V. S. cuios ojos vieron el estado en que se me entregò, y aquel en que oy subsiste formal y materialmente su establecimiento.

A continuación, el rector Menéndez Valdés pasa a exponer tres razones que entiende serían suficientes para justificar la conversión de la obra pía fundada por Valdés Salas, a fin de ascender su Colegio de San Gregorio a Estudios mayores, con unas premisas dignas de conocerse en su integridad:

37 In marg. "Proyecto del señor Dr. D. Ygnacio Menendez Valdes". 
Teniendo la aprobazion de los maiores theologos de España ${ }^{38}$, del Excmo. Señor Patrono ${ }^{39}$, de los señores obispos de este obispado, el actual ${ }^{40}$, y el señor Avello ${ }^{41}$, y de quantos hombres de juicio a fondo y con todas circunstancias han entendido el proyecto, espero a estos se añada el grande de V.S. como el mas inmediatamente interesado.

Supongo ante todas cosas que los estudios de estta casa se instituyeron por su fundazion precisa y necesariamente para los Rudimentos de la Latinidad, porque en el tiempo que se establecio, estaba tan destituida de Doctrina toda la Provincia, que se buscavan para parrochos los que solo supiesen leer Latin; y porque en aquellos años hera tal el concurso de estudiantes, a los estudios de ella, que hasta en los portales se enseñaba, por no caver en las Aulas.

Fue tan provechosa y tan útil entonces, como se be por el frutto de haver dado Maestros para todo el Prinzipado, de manera que a V. S. consta, no solo que en todas las Villas, sino que aun en muchas Aldehuelas, ay oi estos estudios.

De aquí nació hirse aminorando en esta Casa aquel efecto para que fue creado. Pero sobre todo, después que se fundò el Colegio de San Mathias de los Padres de la Compañía, vino a quedar quasi desierta, porque, publico y notorio es, Señor, que sus Aulas atraen a si y a su enseñanza quasi el todo del Pueblo, todo esto es publico y notorio.

De aquí se infiere, haver zesado la causa ympulsiba, y que movio al piadoso corazón del Excelentisimo señor Fundador a esta fundazion y de creer es, que suspirando su amoroso corazón por el alivio y educación de los pueblos de toda la Provincia, viendo estta socorrida en la parte que en sus días no lo estaba, dirigiría los deseos de su corazón

38 La conservación en el AHN de una de las dos piezas del expediente, y la destrucción de los archivos asturianos, impide saber cuáles fueron los teólogos y juristas que redactaron unos dictámenes favorables a la conversión de la obra pía.

39 Se trata del Conde de Miranda y Duque de Peñaranda, en quien recayó el patronato.

40 Era D. Gaspar Vázquez de Tablada.

41 Se trata de D. Juan Avello Castrillón. 
al socorro, que mas necesitase, como entonces lo hizo en los estudios de Gramatica, y si hubiese contemplado la necesidad que ay, de un Colegio en que sus becas fuesen de maiores estudios, no hai duda lo ejecutase asi su Paternal cariño.

Esta, Señor, es la razon de los Theologos, si la causal es verdadera, podría V. S. palparlo con indagar el concurso de estudiantes, a unas y otras Aulas de la Compañía, y de este colegio, tomándose juramento a los Maestros de este, de las horas que gasta en su ejercicio, y del numero de discípulos, quienes, y si muchos de ellos se vinieron huyendo de la Compañía.

Esto es todo tan claro como la luz del Sol. 


\section{Referencias}

AAO. Libro de actas municipales. Sign. A-70. Año 1749, fols. 37v-38r: Ayuntamiento ordinario de 11 de marzo de 1749.

AAO. Libro de actas municipales. Sign. A-70. Año 1749, fols. 43v-44r. 52v-54v.

AAO. Libros de Acuerdos. Sign. A-14, fol. 848r.

AAO. Sign. C-8, fols. 1r-42r. Copia de 1642.

ACO. Libro de actas capitulares. Sign. 9, fol. 36r.

AHN. Sección Consejos. Leg. 27000-2, exp. 5, fol. 1rv.

AHPA. Sección protocolos. Escribano: José de la Fuente. Año 1746. Sign.7727, fols. 194r-195r.

Ballina, A. H. (1979). El Seminario de Oviedo. Rememoración jubilar. 1954-1979, Oviedo 1979.

Bussi, E. (1939). La formazione dei dogmi di diritto privato nel diritto comune. (Contratti, successioni, diritti di famiglia), Padova.

Canella, F. (1985). Historia de la Universidad de Oviedo y noticias de los establecimientos de enseñanza de su distrito (Asturias y León), $2^{\underline{a}}$ ed. ref. y ampl., Oviedo 1903-1904, reimpr. facs., Oviedo.

Carpio, F. (1638). De executoribus et commissariis testamentariis libri quatuor, Ursaone, fols. 97v-111v, cap. XXI-XXII.

Coing, H. (1996). Derecho privado europeo, t. I. Derecho común más antiguo (15001800). Trad. de la ed. alemana y apostillas de A. Pérez Martín, Madrid.

Dávila, G. G. (1986). Teatro eclesiástico de la Santa Iglesia de Oviedo. Vidas de sus obispos y cosas memorales de su obispado, Madrid 1635, fol. 64rv; Oviedo 1986.

de Carballo, L. A. (1958). Linajes asturianos: edic. preparada por el P. J. M. Patac de las Traviesas, S. I., gijón 1987; id., Cisne de Apolo: edic. de A. Porqueras Mayo, 2 vols., Madrid.

García, S. J. (1992). Los jesuitas en Asturias, dos vols., Oviedo 1991-1992, especialmente t. I.

García, S. J. (2000). Aproximación a la biografía hispana de don Benito de Lué y Riega, en Studium Ovetense XXVIII.

García, S. J. (2014). El doctoral ovetense Pedro Cienfuegos, Grado (Asturias) 1642 - + Oviedo, 1684, en REDC 176.

García, S., J. (1992). Los jesuitas en Asturias, dos vols., Oviedo 1991-1992, especialmente t. I, pp. 204-246.

Marta, G. A. (1623). Summa totius successionis legalis quatuor partibus complexa, Lugduni, col. 1094, 
Mayo, A. P. (1991). El período segoviano (1622-1628) de Luis Alfonso de Carballo y el misterio de su libro asturiano desvelado por..., Oviedo 1991.

Novalín, J. L. (1968). El inquisidor general Fernando de Valdés (1483-1568): su vida y su obra (Vol. 2). Universidad de Oviedo.

Novalin, J. L. (1986). Las visitas ad limina de los obispos de Oviedo (1585-1901). Una fuente eclesiástica para la historia de Asturias, Oviedo.

Novalin, J. L. (1986). Las visitas ad limina de los obispos de Oviedo (1585-1901). Una fuente eclesiástica para la historia de Asturias, Oviedo.

Novalin, J. L. (1986). Las visitas ad limina de los obispos de Oviedo..., Oviedo. Aunque fecha su óbito en 1747.

Penzol, P., (1932). El P. Luis Alfonso de Caballo, historiador y preceptista (1575?1630?), Madrid.

Risco, M., O. F. M. (1795). España Sagrada. Tomo XXXVIIII. De la Iglesia exenta de Oviedo..., Madrid.

Risco, M., O. S. A., (1795). España Sagrada. Tomo XXXVIIII. De la Iglesia exenta de Oviedo dssde el medio del siglo XIV hasta fines del siglo XVIII, Madrid.

Ruano, E. B. (1970). La fundación del Colegio de 'San Gregorio' de Oviedo, en Simposio 'Valdés Salas'. Oviedo 8-11 diciembre 1968, Oviedo: Universidad de Oviedo.

Rubio, R., J. J. (1989). El favor iuris de las causas pias ante la integibilidad de la legitima en el Derecho común e hispano, en Apollinaris 66.

Sánchez, J. G. (1987). Notas sobre la provisión de las becas del Colegio de San Gregorio de Oviedo durante el siglo XVII, BIDEA 116 (1935) 947-964; id., Oviedo.

Sánchez, J. G. (1992) Consideraciones histórico-jurídicas referentes a la fundación de la Universidad de Oviedo, en Studium Ovetense 12 (1984) 59-108; id., Notas referentes a la fundación de la Universidad de Oviedo, en BIDEA 139.

Tuero Bertrand, F. (1979). La creación de la Real Audiencia en la Asturias de su tiempo (siglos XVII-XVIII), Oviedo, IDEA.

Viñayo, A. (1955). El Seminario de Oviedo: apuntes para el primer siglo de su vida, 1851-1954, Oviedo 1955. 